\title{
El Frío como Símbolo en "Los Pozos" de Amado Nervo
}

\begin{abstract}
A PESAR de la extensa bibliografía sobre Amado Nervo, su poesía ha recibido realmente poca atención crítica en los últimos años, debido quizá a un súbito cambio en su valoración, a un cierto eclipse de su fama literaria. Las Obras completas, recientemente publicadas por Francisco González Guerrero y Alfonso Méndez Plancarte, ${ }^{1}$ representan más bien un deseo de establecer los textos definitivos que un renacimiento de interés. Numerosas razones se pueden aducir para explicar tal cambio. El hechizo personal del poeta, que con frecuencia no logró convertirse en poesía, tal vez conquistó a los críticos de su tiempo..$^{2}$ En cambio advertimos ahora en Amado Nervo un intelecto mimético que a veces era incapaz de distinguir con certeza entre una novedad brillante y pasajera y una intuición sentida. Esta falla en el discernimiento filosófico a menudo se confunde con el eclecticismo, palabra tan manida dentro de la crítica nerviana. ${ }^{3}$ Por fin, contribuye a este cambio de nuestra apreciación el concepto equivocado que tenía Nervo de la naturaleza de la sencillez poética. Esta última característica fue recibida por muchos lectores como una vuelta a la sencillez de la vieja tradición popular, vuelta que parecía en cierto modo una protesta contra lo excesivo del modernismo preciosista. Seducidos los lectores por

1 Amado Nervo: Obras completas (Madrid, 1956), 2 tomos. Todas las referencias a esta publicación serán al segundo tomo y se citarán en el texto mismo de este estudio.

2 Véase la introducción a la poesía de Nervo en el libro citado, páginas 1245-1259. Sobre este punto dice Ortiz de Montellano, "Nada tiene... de extraño que sus versos, recitados con su propia voz, que magnetizaba a su auditorio, tuvieran una existencia y un influjo que pierden en las páginas del libro; que su figura, la atracción de su personal estilo, sea comentada por todos los que le conocieron". Figura, amor y mueyte de Amado Nervo (México, 1943), p. 32. Sobre la fama actual de Nervo, véase: Luis Leal, "La poesía de Amado Nervo: a cuarenta años de distancia", en Hispania (March, 1960), pp. 43-47.

3 Seria inútil mencionar a todos los críticos que han escrito sobre el eclecticismo de Nervo; el estudio de Esther Turner Wellman, Amado Nevro Mexico's Religious Poet (New York, 1936) es un ejemplo.
\end{abstract}


la sinceridad de esta actitud, llegaron a considerarle como el mejor poeta - - después de Darío - de la América Hispana. Lástima que los lectores no se acordaran más, en las primeras décadas del presente siglo, de Ismaelillo o de los Versos sencillos de Martí. Una ligera comparación hubiera rectificado tan precipitada valoración. ${ }^{4}$

No obstante todas las fallas de Nervo en sus libros hay sin embargo poesías que tienen mérito e interés. Entre éstas está la poco citada "Los pozos", una fantasía que forma parte de la colección menos apreciada de sus obras poéticas, El estanque de los lotos. Es instructivo notar que el referido poema se apega más a la técnica y meta del arte novelístico nerviano que a las orientaciones de sus versos. Los elementos que más eficazmente impulsan el desarrollo de esta narración son aquellos sugeridos mucho antes por las fantasías de Hoffmann o Poe, y más tarde, en el mundo hispánico, por los cuentos y leyendas de Bécquer. A pesar de of recer poco de originalidad en cuanto a los recursos formales del poeta, este poema muestra una actitud hacia la vida que es fundamental en su obra. Esta actitud se objetiviza en tres símbolos que habían recibido anteriormente largo proceso de elaboración dentro de su poesía y que son, el agua, la sed y el frío. Estos símbolos desempeñan papeles recíprocos de continua transformación, no sólo en "Los Pozos", sino en muchas otras composiciones. Creemos que se podría ahondar el conocimiento de la obra de Nervo aislando y analizando uno de ellos: el "frío", destacando el papel que ejerce en "Los pozos". Cito el texto completo para facilitar el comentario:

"-iMadre, madre, me muero de sed!

Si supieras qué sueño he tenido..."

- ¿Qué soñabas, mi amor?"--"Pues soñaba

que vivía en un rato planeta, glacial, cristalino.

"En un raro planeta de hielo. habitado por seres blanquísimos $y$ de un rubio ideal, que moraban muy felices en medio del frío.

"Los enormes, translúcidos témpanos azulados, a la luz de un tímido satélite verde, fingían fantasmas

4 Compárese "Cultivo una rosa blanca..." de Martí con "Venganza" (p. 1600) o con "Si una espina me hiere..." (p. 1739) de Nervo. 
envueltos en linos

irreales, o montes absurdos

de amatistas, topacios, zafiros...

"Y recuerdo también, madre mía

que en ocultos sitios

llenos de misterio,

vigilados siempre por custodios rígidos,

gigantescos, mudos, había unos pozos,

unos pozos hondos. .., hondos, ide aire líquido!

"Era ciento ochenta grados bajo cero

su temperatura..."

- "No delires, hijo!"

- ¡Ciento ochenta grados bajo cero madre!

$\mathrm{Y}$ si por descuido

un bloque de hielo caía en un pozo,

hirviendo al contacto de aquel cuerpo "igneo",

se alzaban columnas de "vapor de aire"

lanzando, rabiosas, sus agudos silbos...

"Estos pozos estaban cubiertos, y muy recatados y muy escondidos.

... Pero yo, muriendo de sed, fuí a buscarlos

fuí a buscarlos, madre, por entre los riscos

de hielo, con ansias de apagar la lumbre

de mis fauces ávidas (mientras que, dormidos, los rubios guardianes yacían al borde

de cada hoyo estigio).

"Y abriendo la tapa de uno, del más grande, por inadvertencia resbalé al abismo.

¿Resbalé a la sima negra, en cuyo fondo

había aire líquido!

“ $\mathrm{OH}$, qué sensaciones deliciosas, madre!, ¡qué estupendo frío!

¡Por fin a estos labios de brasas, la fuente mayor de frescura refrigeraríalos! 
"iPero no acababa de caer al fondo!

¡No llegaba al líquido!

Nunca terminaba mi derrumbamiento:

¡sólo iba creciendo mi frío!

"...A Al fin llegué, madre, llegué, qué ventura!

¡qué baño divino!

¡qué inmersión silenciosa en las linfas

insondables del pozo dormido...!

"Mas ¡ay!, que al contacto de aquellos caudales, de aquellos caudales claros y tranquilos, sentí que tri cuerpo se cristalizaba como un gran diamante volviéndose nítido. ¡Era yo un cadáver de cuarzo! ¡Un cadáver infinitamente frío, frío, frío!

"Pero libre, madre, de sed para siempre! ¡de esta sed inmensa que ya no resisto!

¿Por qué he despertado? ¿Por qué volví al horno de este lecho... ? ¡Madre, tu vaso está tibio! $\ldots$.. ¿lévatelo! ¡Quiero que me des un vaso de aquel aire líquido!" (pp. I806-1807).

Desde varios puntos de vista este poema reúne lo esencial de los varios mundos hacia los cuales aspiraba Nervo en los vuelos de su imaginación. "Tengo la enfermedad sutil de lo absoluto", (p. I753) exclamó en uno de sus versos de Elevación, y casi toda la poesía de sus últimos años brota de esta "enfermedad". Busca Nervo un universo distante, ascendiendo desde la noche terrestre hacia el cielo de planetas, astros y constelaciones, para lo cual transpone todo lo físico - astros, planetas- a un plano simbólico y espiritualista. La realidad de los cielos se quiebra para que quede al descubierto otro mundo--el del sueño-en que se encuentra primero la eterna belleza suntuosa y sensual del ensueño modernista, ${ }^{5} \mathrm{y}$ más tarde la negación total de lo físico e intelectual en la suspensión de todo sentir y pensar.

Este anhelo de ascender a otra realidad le llevó*a abrazar, con un

5 Véase, por ejemplo, "Según todos", "El prisma roto", etc. 
entusiasmo y capacidad sorprendentes, muchas declaraciones de experiencias extra-sensoriales y teorias anti-racionalistas en boga. ${ }^{6}$ Desde luego, participó Nervo en el descubrimiento occidental del espiritualismo del Oriente. Siendo poeta de su época, empezó con la cbinoiserie típica que formaba parte del inventario modernista, pero pronto dejó de lado estas curiosidades para adentrarse más a fondo en el misticismo oriental. Aparte del curioso trueque del simbolismo y parnasianismo en la cronología de su desarrollo poético, la evolución poética de Nervo es una historia de la interiorización progresiva de su visión.

Es de notar que esta interiorización angustiada se manifiesta, en su expresión más absoluta, dentro de una forma a la vez narrativa, simbólica, y, en cierto sentido, impersonal. La resignación, o tranquilidad, de Elevación (x917) es mucho más verdadera, más persuasiva, que la paz negativa que caracteriza a $E l$ estanque de los lotos (I9I9). Aquí, repetidas veces, el poeta pide el olvido, la insensibilidad total. Este desasosiego tiene muy poco que ver con el amor y la unión universal de aquella obra anterior. Es, en efecto, esta misma angustia, fuertemente personal, la que intensifica el subjetivo escudriñar. En El estanque de los lotos el enfoque es estrictamente limitado y subjetivo, a pesar del mecanismo narrativo y dramático de algunos de los poemas. El hecho de que hay menos declamación en primera persona no quiere decir que haya menos concentración subjetiva. La vista se dirige mucho más al interior: "El fenómeno, lo exterior, vano fruto/ de la ILUSION, se extingue: ya no hay PLURALIDAD, / y el yo, extasiado, abísmase por fin en lo ABSOLUTo..." (p. I779).

"Los pozos" tiene significado especial, no sólo porque reúne aspectos esenciales de la búsqueda espiritual de Nervo, sino porque expresa esta angustia, quizá mejor que otros de sus poemas, en términos estéticos. Es decir, en este poema, se construye la pregunta atormentada por medio de recursos de símbolo y de escena que permiten al lector participar del estado psíquico que experimenta y crea el poeta. En otras ocasiones, desgraciadamente frecuentes, Nervo se satisface con meras descripciones rimadas de sus sentimientos que la mayor parte de las veces dejan de conmover al lector.

Además de ciertos valores artísticos, "Los pozos" sintetizan uno de los puntos esenciales de la temática y del simbolismo de Nervo. Esto, a pesar de que el "amor" tiene el papel dominante en su obra. Este amor

- Véase: Ortiz de Montellano, op. cit., p. 43; Concha Meléndez, Amado Nervo (New York, 1926); y Turner, op. cit. Estos estudios abundan en noticias sobre tales creencias de Nervo. El propio poeta también declara su fe en el espiritualismo; véase la nota número 7 . 
abarca tanto lo sensual como lo metafísico; empieza con cierto patetismo romántico en Perlas negras, se ensancha en un panteísmo vuelto franciscano en "La hermana agua" o "Las voces", de acuerdo con la boga del franciscanismo de los primeros años del presente siglo, y se resuelve al final en una doctrina de amor universal, cósmico.

Se interrumpe con frecuencia el ritmo armonioso del Cosmos con latidos disonantes de duda y de desesperación. Estos momentos generalmente se manifiestan por un tono de confesión, expresado dentro de un léxico anticuado y neo-romántico. En consecuencia, los símbolos dominantes - la noche: lo desconocido; la sombra: la tristeza; el cielo: la aspiración; el calor: la pasión - tienen poco vigor. Los tropos y figuras revelan cierta falta de visión poética y poca preocupación estética, que no se disculpan por el hecho de que Nervo renuncie a la "literatura" y a todo intento "poético". No obstante, en la elaboración de "Los pozos", sale Nervo del marco convencional y logra crear y comunicar un estado psíquico y poético de interés en cuanto a su obra en conjunto. Lo sintético de este poema se realiza por medio del cambio y acumulación de significados que experimenta el sentido simbólico del "sueño" y del "frío" a lo largo de su poesía.

El mundo del sueño se examina y se define repetidas veces en su obra y lo trata Nervo de una manera a la vez extravagante y tradicional. Indudablemente los descubrimientos de Hoffmann, Poe y los simbolistas son los aspectos del sueño que más le fascinaban. Lo mismo que a sus modelos, le intrigaban a Nervo las posibilidades imaginativas que le of recía esta realidad onírica y las infinitas analogías psicológicas y metafísicas que a continuación sugería. $\mathrm{Y}$ además, las posibilidades que esa realidad of recía como santuario, como región tranquila y ausente de la tiranía de los apetitos, empezaban a dominar su concepto metafísico de esa segunda realidad. Antes de expresar con claridad este concepto, definió la intensidad y naturaleza de su anhelo de un mundo nuevo, de la región de paz en donde queria habitar:

¡Oh, Siddharta Guatama!, tú tenías razón:

las angustias nos vienen del deseo; el edén consiste en no anhelar, en la renunciación completa, irrevocable, de toda posesión; quien no desea nada, dondequiera está bien. 
La renunciación de todo deseo parece sugerir al poeta el camino más directo por el cual se efectúa tal renunciación:

La Muerte, nuestra Señora

está llena de respuestas:

de respuestas para todos

los por qués de la existencia.

Silencio de los silencios

tal vez llamarla debieran;

¡Qué maternal su regazo!

¡Y qué benigna y qué tierna

su boca, que nos dará,

en voz baja, las respuestas

a los por qués angustiosos

que torturan la existencia!

("La muerte, nuestra señora", p. I604-1605).

Aunque la muerte puede ser el anhelado fin de una existencia dolorosamente sensitiva, es, no obstante, una solución que queda fuera del campo de la acción posible.7 Entonces se ve obligado el poeta a buscar otro camino:

¡Plácido tu callar es, memoria!

¡Déjame para siempre, fantasma!

Mística desnudez de deseos,

búdico reposar de nirvanas,

7 La muerte de su amada, en la primavera de 1912, casi le llevó al suicidio. Según el poeta, desistió por miedo de quebrar irrevocablemente el lazo que tenía con el espíritu de ella: "Mas hablemos del segundo modo de que ella me sea restituida, que es el de ir a buscarla por el camino real de la muerte. ‘ Desgraciado! -exclamó la Espírita de Théophile Gautier, estrechando contra su corazón de fantasma a Guido, que iba a suicidarse- ¡No hagas eso! iNo te mates por unirte a mí! ¡Tu muerte, así provocada, nos separaría sin esperanza, y abriría entre nosotros abismos que millones de años no bastarian a franquear! jVuelve en tí! Soporta la vida, que, por larga que sea, no dura más que la caida de un grano de arena ... Para soportar el tiempo, piensa en la eternidad, en que podremos amarnos siempre'. $\mathrm{Y}$ he aquí cómo inveteradas ideas espiritualistas, que desde mi infancia anclaron en el alma, ahondadas por tantas lecturas, me han impedido la muerte; gracias a ellas... ini puedo vivir ni puedo moriv!" (Obras completas, tomo II, p. 1120. Véase también su carta a Rubén Darío, enero 27 de 1912, op. cit., p. 1133). 
¡eso nomás quieren

mi cuerpo y mi alma!

$$
\text { ("Eso nomás", p. r639) }
$$

Conviene notar que estas tres protestas forman parte de Serenidad (I914), colección en que el poeta afirma haber superado, por medio de la sencillez cultivada, la incomodidad metafísica de su juventud.

En "Tedio", uno de los mejores poemas de la colección en cuanto al acierto formal y a la intensidad de la expresión, Nervo comunica el desasosiego que repetidamente motiva su arte y que busca resolverse en la existencia de una expresión autónoma que sea simbólica, internamente consistente y que tenga una identidad que sea independiente de la experiencia personal del poeta. La voluntad enérgica y positiva de librarse de las tensiones que traen las sensaciones, los deseos, y el ennui, tiene que sufrir una transformación, una inversión, antes de ser posible la elaboración de "Los pozos". La deseada liberación se va logrando primero gracias a la negación. La forma sintáctica de la expresión nace y se concreta en "Al cruzar los caminos".

Al cruzar los caminos, el viajero decía -mientras, lento, su báculo con tedioso compás las malezas hollaba, los guijarros hería-; al cruzar los caminos, el viajero decía: "¡He matado el Anhelo, para siempre jamás!

"iNada quiero, ya nada, ni el azul ni la lluvia, ni las moras de agosto ni las fresas de abril, ni amar yo a la trigueña ni que me ame la rubia, ni alabanza de docto ni zalema de vil!

"Nada quiero, ya nada, ni salud ni dinero, ni alegría, ni gloria, ni esperanza, ni luz. ¿Que me olviden los hombres, y en cualquier agujero se deshaga mi carne sin estela ni cruz!

"Nada quiero, ya nada, ni el laurel ni la rosa, ni cosecha en el campo ni bonanza en el mar, ni sultana ni sierva, ni querida ni esposa, 
ni amistad ni respeto... Sólo pido una cosa:

¡Que me libres, oh Arcano, del horror de pensar!

$\ldots \ldots \ldots \ldots \ldots \ldots \ldots$ (p. 1774-1775)

La enumeración negativa es típicamente budista y, desde el punto de vista técnico, una sencilla inversión de la acumulación tradicional que se ve en la declaración ritualista. Fracasa el poema, sin embargo, porque el poeta se niega a separarse por entero de su creación y labrarla como algo externo. Nervo persiste en forzarnos a contemplarle a él más que al poema. En "Tedio", en cambio, se aleja de su poema, después de haber identificado la experiencia, dándole su propio movimiento y solución estética.

La eliminación de objetos de la experiencia física y sensible que logra esta enumeración negativa, es un paso necesario hacia la formulación de un mundo imaginativo en donde puede ser neutralizada la sensación por medio de la acción simbólica. En "Los pozos" el ascenso de la fantasía hacia el "raro planeta" es un lanzarse por una inercia total; toda acción se congela, la voluntad está suspendida en el frío y el líquido mágico es lo absoluto de la insensibilidad:

"...¡Al fin llegué, madre, llegué, qué ventura!

¡qué baño divino!

¡qué inmersión silenciosa en las linfas

insondables del pozo dormido...!

"Mas iay! que al contacto de aquellos caudales, de aquellos caudales claros y tranquilos, sentí que mi cuerpo se cristalizaba como un gran diamante volviéndose nítido. ¡Era yo un cadáver de cuarzo! ¡un cadáver infinitamente frio, frio, frio!

("Los pozos")

El carácter episódico de este poema permite al poeta apartarse de su creación; también lo obliga a componer en términos de objetos y relaciones en vez de describir su estado emocional íntimo. Esto resulta para Nervo una ventaja, ya que una característica de sus esfuerzos líricos consiste en insistir demasiado en lo meramente autobiográfico. La naturaleza 
narrativa de "Los pozos", en cambio, le hace más fácil mantener cierta distancia estética. En "Edelweiss", antes de r9oo, había hecho Nervo algo semejante, no sólo en la estructura episódica sino también en el simbolismo esencial. El origen de la forma de "Los pozos", ligeramente concebida como es, tiene que buscarse, no obstante, en el estilo de su prosa y no en sus versos. La afición de Nervo por lo imaginativo y lo chocante se manifiesta con más éxito en su prosa - puede ser que por las mismas razones de distanciamiento ya comentadas. La forma exterior de "Los pozos" tiene muy poco que ver con los recursos técnicos de la poesía; aún más, es evidente que el poema deja mucho que desear con respecto a la forma poética. Lo extraordinario es que "Los pozos", a pesar de sus insuficiencias formales, consigue comunicar y sostener, quizá mejor que ningún otro texto de Nervo, la experiencia de la supra-realidad que intentaba aislar y cristalizar en verso y en prosa. En su conocido ensayo "La cuarta dimensión" ( 1917 ), trata de expresar, en términos abstractos, la realidad buscada y el papel descubridor que desempeña la poesía en tal pesquisa:

El éxtasis poético, semejante a todos los éxtasis, no es más que el acceso a una dimensión nueva y la consiguiente deleitosa y admirable sen. sación de que se han quebrantado los limites que encierran nuestras percep. ciones del univetso como rejas invisibles. Una noción de libertad espaciosa, de ligereza, de descentración, de despego de todos los aglutinamientos, invade paradisíacamente nuestra alma.

El cerebro, por un momento parece poner al espíritu menos obstáculos para la inmersión de éste en una dimensión desconocida, en que ya no hay más que unidad, una pacífica y jubilosa unidad.

Lo negro y lo blanco, el mal y el bien, el dolor y la alegría, cesan de existir. Comprendemos que eran sólo limitaciones. El conjunto es indescriptible: de una armonía infinita, para la cual no hay todavía una palabra en nuestros léxicos.

Esta armonía está aún más allá, mucho más allá de la Paz. (p. 911).

En "Los pozos" Nervo encuentra este otro mundo que está "mucho más allá de la Paz". Es un mundo helado, de piedras preciosas que diluyen todo su color en lo blanco y toda su forma y brillantez en la irregular e inmóvil geometría del hielo. El frio ha cambiado de calidad y sentido en esta etapa de la poesía de Nervo. Examinemos la transformación.

La primera ocasión digna de mención en que se emplea el frió como 
equivalente psíquico, ocurre en "La hermana agua", en la sección titulada "El hielo":

Para cubrir los peces del fondo, que agonizan de frío, mis piadosas ondas se cristalizan, y yo, la inquietüela, cuyo perenne móvil es variar, enmudezco, me aduermo, quedo inmóvil. ¡A A ! Tú no sabes cómo padezco nostalgia de sol bajo esa blanca sábana siempre fría.

Tú ignoras esa angustia; mas yo no me rebelo, y ansiosa de que en todo mi Dios sea loado, desprendo radiaciones al bloque de mi hielo, y en vez de azul oleaje soy témpano azulado.

Mis crestas en la noche del polo con fanales refleja el rosa de las auroras boreales... (p. I 383$)^{3}$

El agua se personifica en un estado congelado, estado lamentable a causa de estar tan lejos de los cálidos rayos del sol y cuyo único mérito radica en la intensidad peculiar de una belleza reflejada. En efecto, en su esencia la imagen es visual.

Vemos en "Horas grises", poema posterior, otra presentación aún más típica del símbolo, que se repite muy a menudo a lo largo de la poesía de Nervo:

Ya llega el otoño con lluvias y nieblas... las hojas marchitas arrastran los vientos; mas van con nosotros las cosas ya viejas que llevamos dentro.

En vano queremos cubrirnos de flores, callar nuestras penas, mostrarnos contentos: no pueden las glorias del mundo quitarnos las nieves de dentro.

Las risas alegres parecen banales en bocas jocundas que invitan al beso, 
que todo lo cubre con velo de muerte

la nieve de dentro.

La dicha esperada murió con los sueños

que ayer nos hicieron labrar un soneto:

los libros, $\tan$ solo, nos quitan a veces

la nieve de dentro.

$Y$ ahora esperamos que pase el otoño

que llegue el invierno con todos sus hielos;

el frío, que, fuera, será más benigno

que el frío de dentro. (P. I5II).

El empleo del frío y de la blancura para expresar la disminución del calor y la disipación paulatina de la vitalidad que termina en la muerte, es una progresión temática que vemos con frecuencia. La imagen ha acogido un significado limitado $y$, en general, una índole simbólica que se realiza sólo en tanto logra Nervo revitalizarla por medio de una dicción y forma apropiadas. Una ligera pero importante modificación del símbolo ocurre en la colección posterior, Los jardines interiores (1905). "Increpación" concluye con una súplica que no halla respuesta: "La eternidad es muda y el enigma cobarde. ./ Hermana, tengo frío; el frío de la tarde". (p. x 539) Se ha extendido el símbolo y llega a ser esta vez más abstracto. Ahora el frío es el enigma inmutable, indiferente e impenetrable. ${ }^{8}$

En esta etapa, la sensación de aislamiento equivale a un sentirse abandonado, mientras que la soledad posterior de "Los pozos" será para él un refugio, la anhelada tranquilidad. El empleo del frío para expresar y caracterizar aspectos negativos de la existencia sigue dominando la colección En voz baja (I909). En "Muerta", de este libro, se manifiesta una función simbólica del frío que es completamente tradicional. Es de notar, sin embargo, que los elementos de la elaboración metafórica son parecidos, de manera significativa, a los que se encuentran en "Los pozos". La función y resultado en estos versos son, no obstante, muy distintos:

Muy vasta, muy distante, muy honda, sí, muy honda, ipero muy honda!, debe ser, iay!, la negra onda

8 Parecida imagen se encuentra en "Arcanidad" de Serenidad (1914): "Cuando me asomo a mí como a un cristal/ diáfano, sí, mas insondable, siento/ en redor un sutil vaho de enigma, / un glacial calosfrío de misterio..." (p. 1643) 
en que navega su alma como un tímido albor, para que aquella madre tan buena no responda ni se estremezca al grito de mi infinito amor.

Glacial, sin duda, es esa zona que hiende, fría, ¡oh, sí!, muy fría, ipero muy fría!, debe estar, para que no la mueva la voz de mi agonía, para que todo el fuego de la ternura mía su corazón piadoso no llegue a deshelar.

Tal vez en un planeta bañado de penumbra sin fin, que un sol opaco, y casi extinto, alumbra, cuitada peregrina, mirando en rededor ilógicos aspectos de seres y de cosas, absurdas perspectivas, creaciones misteriosas, que causan extrañeza sutil y vago horror. $\ldots \ldots \ldots \ldots \ldots \ldots \ldots \ldots \ldots \ldots \ldots \ldots \ldots \ldots$ p. I572-1573)

Conviene señalar que Nervo pudo adaptar el símbolo del "frío" a nuevas actitudes sin abandonar por completo los significados anteriores. Aunque, en general, las nuevas funciones del símbolo tendían a reemplazar las antiguas, hay, no obstante, cierta amplificación acumulativa.

Con los primeros versos de Elevación ( 1917 ) vemos claramente el papel que el mundo de hielo y frío ha de desempeñar en "Los pozos". Inicialmente en "Primera página" y luego en "Jaculatoria a la nieve" se ensancha y se clarifica el símbolo:

iOh, Atcano, para subir a ti, dáme la mano!

Dáme, noche encendida, luz; y tú dáme, vida, (pues el viaje es muy largo, el tiempo breve), más tiempo aún para escalar la nieve perpetua, donde el sol no tiene velos ni hay ya la "azul mentira" de los cielos, sino el glacial vacío, el astro hirsuto, con sus lenguas de hidrógeno inflamado, lamiendo la negrura del abismo. ...Y después, el pavor de lo ABsoluto 
donde está el INCREADO,

en silencio, mirándose en sí mismo.

\section{("Primera página")}

¿Qué milagrosa es la Naturaleza!

Pues ¿no da luz la nieve?

Inmaculada

y misteriosa, trémula y callada, paréceme que mudamente reza

al caer...

$$
\text { ¡Oh, nevada! }
$$

tu ingrávida y glacial eucaristía

hoy del pecado de vivir me absuelva

y haga que, como tú, mi alma se vuelva

fúlgida, blanca, silenciosa y fría. (p. I $72 \mathrm{r}$ )

\section{("Jaculatoria a la nieve")}

Es de interés señalar que "Jaculatoria a la nieve" se compuso en I9I4, tres años antes de ser incluida en Elevación, hecho que indica que las nuevas posibilidades del símbolo tomaban forma, aun cuando el poeta seguía cultivando los aspectos más tradicionales.

Los temas de estos poemas nos llevan por fin al mundo imaginario de "Los pozos", en donde el hielo y la azulada blancura del planeta establecen el escenario y dan lugar a la creación de un nuevo elemento: el líquido mágico. El significado de este cambio consiste en que se permite ahora una variación entre los atributos del objeto metafórico. Se ve el hielo; se siente el frío con el tacto, pero es en esencia estático; incluir el líquido permite una sensación de inmersión, de suspensión completa del sentir. Tiene éxito hasta este punto la nueva elaboración; lástima que su elección de "aire líquido" deforme inconscientemente la imagen a causa del tono un tanto científico.

Esta intensa concentración en todo lo helado y frío quizá pueda calificarse de excesiva. Es curioso, sin embargo, que una tendencia análoga se encuentra, aunque con otros fines, en Mallarmé, quien evoca imágenes y objetos casi idénticos a los de Nervo. Es bien conocido su "Le vierge, le vivace et le bel aujourd'hui...", pero además nos llaman la atención trozos como éste: 
En vérité, je voyage, mais dans des pays inconnus, et si, pour fuir la réalité torride, je me plais à évoquer des images froides je te dirai que je suis depuis un mois dans les plus purs glaciers de l'Esthétique-qu'après avoir trouvé le Néant, j'ai trouvé le Beau,-et que tu ne peux t'imaginer dans quelles altitudes lucides je m'aventure. ${ }^{9}$

La presencia en "Los pozos" de múltiples colores traídos como contraste de la blancura, el agudo sentido táctil de las imágenes, la amplitud sugestiva de la oscilación entre la luz cegadora de la superficie y la negrura de los pozos maravillosos, cristalizan momentáneamente la realidad poética en que Nervo solía vivir y que, en este poema y en varios de sus cuentos, adquiere una definición marcada. Estas excursiones a tierras imaginadas traen, sin embargo, sus consecuencias; los peligros -o recompensas- de quedarse demasiado en estas regiones del espíritu se declaran nítidamente en "La perla":

Todas las noches lanzas tu conciencia al abismo enigmático del sueño, $y$ todas las mañanas la recoges, la pescas en la red de tu cerebro;

mas un día, tan hondo habrá caído, que ya no la hallarás... El mudo piélago, como perla de Oriente, misterioso, la guardará en su seno.

(El estanque de los lotos, P. I781).

Parece evidente que "Los pozos" representa al menos uno de los elementos esenciales en la formación de Nervo como artista. Aunque la búsqueda no sigue una trayectoria directa en su desarrollo - y éste es el caso de casi todas las invenciones de Nervo- en cambio refleja, en sus contornos generales, el descubrimiento progresivo de un símbolo y de sus posibilidades psicológicas y estéticas. El símbolo se desarrolla también en línea paralela al movimiento de la visión artística que se aleja de la poesía lozana y sensual de las primeras obras. Es un movimiento que, en general, empieza en los jardines artificiales de los modernistas, que le dirige

9 Stéphane Mallarmé, Propos sur la poésie, recueillis et présentés par Henri Mondor (Mónaco, 1946), p. 68 . 
luego a la contemplación intensa de su propia sensibilidad, y que al fin le lleva a tratar de trascender la vida mortal y realizar una especie de existencia cósmica. Por lo común, el arte de Nervo sufre en esta transformación, pero varios de sus poemas más interesantes resultan de este extraordinario viaje. ${ }^{10}$

\section{Ned DAvison}

\section{University of Oregon}

10. Cúmpleme agradecer aquí la ayuda del "General Research Council" de la Universidad de Oregon, que ha facilitado la preparación del presente trabajo. 